\title{
Synthesis of 4,5,6,7-Tetrahydro-1,1-dimethyl-2-(4'-methyl-penta-1',3'-dien- $1^{\prime}$-yl)-indene. A Synthetic Proof of the Chromophoric Structure of a Colour-producing Compound in the Colour Reaction of Retinoic Acid in 74\% Sulphuric Acid
}

\author{
The title compound (3) which involves a new conjugated system, has been synthesised \\ in a geometrically pure form from the indanone (4). \\ Keywords___colour reaction of retinoic acid; tetrahydroindene skeleton; new con- \\ jugated system; Horner reaction; Wittig reaction; visual pigment analogue
}

As the results of the studies ${ }^{1)}$ on the chemistry of a colour reaction (in $74 \% \mathrm{H}_{2} \mathrm{SO}_{4}$ ) of retinoic acid (vitamin A acid) (1) which is known to be closely related to the metabolism of retinol $^{2)}$ and to prevent and inhibit the growth of epithelial tumours, ${ }^{3}$ ) the structure of the main quenched product (isolated as methyl ester) of coloured species was proposed as 2 by its spectroscopic consideration. ${ }^{4}$ ) The striking red colour of 1 in $74 \%$ sulphuric acid $(\lambda 454 \mathrm{~nm})$ was regenerated from 2 by acidification with the $74 \%$ acid Therefore, the compoumd (2) which involves a new interesting conjugated system has been considered to have the same chromophoric structure as the colour-producing compound in the colour reaction of retinoic acid in $74 \%$ sulphuric acid. We now report a synthesis of 4,5,6,7tetrahydro-1,1-dimethyl-2-(4'-methylpenta-1',3'-dien-1'-yl)-indene (3) which corroborates the chromophoric structure of the proposed compound (2) including the tetrahydroindene skeleton.

Formylation of 4,5,6,7-tetrahydro-3,3-dimethyl-1-indanone (4) ${ }^{6}$ with ethyl formate and sodium hydride in dry ether gave the crystalline formyl-enone $\left[\mathbf{5}, \mathrm{mp} 130^{\circ}, \lambda 260,283\right.$ $\left.\mathrm{nm}, v 1665,1600 \mathrm{~cm}^{-1}, \delta 9.95(\mathrm{~s}, 1 \mathrm{H}, \mathrm{OH}), 7.05(\mathrm{~s}, 1 \mathrm{H},=\mathrm{CHOH}), 1.20\left(\mathrm{~s}, 6 \mathrm{H}, \mathrm{gemCH}_{3}\right)\right]$ in $81 \%$ yield. The compound (5) was reacted with hydroxylamine hydrochloride in acetic acid to yield the isoxazole (6) which, without purification, was treated with sodium methoxide in dry ether followed by column chromatographic purification (silica gel, $30 \%$ ether in $n$ hexane) to afford the ketonitrile $\left[7, \lambda 238 \mathrm{~nm}, v 2250,1712,1642 \mathrm{~cm}^{-1}, \delta 3.23(\mathrm{~s}, 1 \mathrm{H}, \mathrm{CO}-\mathrm{CH}-\right.$ $\mathrm{CN})$ ] in $61 \%$ yield from 5 . Sodium borohydride reduction of 7 and subsequent dehydration of the resulting hydroxy-nitrile with phosphorous oxychloride in dry pyridine afforded the dienonitrile $\left[8, \lambda 295 \mathrm{~nm}, v 2200,1633,1537 \mathrm{~cm}^{-1}, \delta 6.89(\mathrm{~s}, 1 \mathrm{H},=\mathrm{CH})\right]$ in $45 \%$ yield which was converted to the dienal $[9, \lambda 318 \mathrm{~nm}, \delta 9.63(\mathrm{~s}, 1 \mathrm{H}, \mathrm{CHO}), 7.09(\mathrm{~s}, 1 \mathrm{H},=\mathrm{CH})]$ by reduction with di-isobutylaluminium hydride in dry toluene. A Horner reaction ${ }^{7)}$ between 9 and diethyl methoxycarbonylmethylphosphonate led to the conjugated triene ester (10) in which the newly formed double bond was confirmed to be trans by its NMR spectrum, [7.51 (d, $J=$ $16 \mathrm{~Hz}, 1 \mathrm{H}, \beta-\mathrm{H}), 5.95(\mathrm{~d}, J=16 \mathrm{~Hz}, 1 \mathrm{H}, \alpha-\mathrm{H})]$. The ester group in the compound (10) was reduced with lithium aluminium hydride followed by oxidation with active $\mathrm{MnO}_{2}$ and subsequent column chromatography $\left(5 \% \mathrm{H}_{2} \mathrm{O}\right.$-deactivated alumina, $5 \%$ ether in $n$-hexane) to

1) K. Tsukida, M. Ito and F. Ikeda, Experientia, 29, 1338 (1973); idem, ibid., 30, $980(1974)$; K. Tsukida, M. Ito, F. Tomeoka (née Ikeda) and A. Kodama, J. Nutv. Sci. Vitaminol., 24, 335 (1978).

2) A. Kleiner-Bössaler and H.F. DeLuca, Arch. Biochem. Biophys., 142, 371 (1971).

3) H. Mayer, W. Bollag, R. Hänni and R. Rüegg, Experientia, 34, 1105 (1978).

4) $2 ; \mathrm{C}_{21} \mathrm{H}_{30} \mathrm{O}_{2}, m / e 314.226\left(\mathrm{M}^{+}\right), \lambda^{5)} 348,333,318$ (sh.), $236 \mathrm{~nm}, v^{5)} 1740,1150 \mathrm{~cm}^{-1}$ (unconj. aliph. ester), $1622,1592 \mathrm{~cm}^{-1}(\mathrm{C}=\mathrm{C}), 958 \mathrm{~cm}^{-1}($ trans $\left.-\mathrm{CH}=\mathrm{CH}-), \delta^{5}\right) 1.08\left(\mathrm{~s}, 12 \mathrm{H}, 4 \mathrm{CH}_{3}\right), 1.92$ (s, $\left.3 \mathrm{H}, 4^{\prime}-\mathrm{CH}_{3}\right), 2.13$ $\left(\mathrm{t}, 2 \mathrm{H}, J=5.5 \mathrm{~Hz}, 7-\mathrm{H}_{2}\right), 3.13\left(\mathrm{~s}, 2 \mathrm{H}, 5^{\prime}-\mathrm{H}_{2}\right), 3.72\left(\mathrm{~s}, \mathrm{CO}_{2} \mathrm{Me}\right), 6.05$ (d, $\left.1 \mathrm{H}, J=10.5 \mathrm{~Hz}, 3^{\prime}-\mathrm{H}\right), 6.31$ $\left(\mathrm{d}, 1 \mathrm{H}, J=15.5 \mathrm{~Hz}, 1^{\prime}-\mathrm{H}\right), 6.44(\mathrm{~s}, 1 \mathrm{H}, 3-\mathrm{H}), 6.61\left(\mathrm{dd}, 1 \mathrm{H}, J=10.5,15.5 \mathrm{~Hz}, 2^{\prime}-\mathrm{H}\right)$.

5) UV were taken in EtOH, IR in $\mathrm{CHCl}_{3}$ and $\mathrm{NMR}$ in $\mathrm{CDCl}_{3}$, respectively.

6) J.-M. Conia and M.-L. Leriverend, Bull. Soc. Chim. Fr., 1970, 2981.

7) J. Boutagy and R. Thomas, Chem. Rev., 74, 87 (1974). 

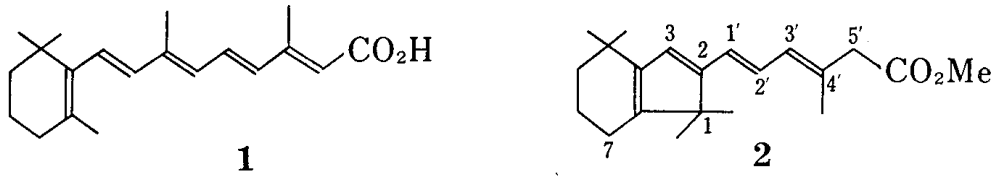<smiles>CC(C)=CC=CC(C)=CC1=C2C(C)CCCC2CCC1C(C)(C)C</smiles>

3<smiles>CC(C)(C)CC(=O)C1=C2CCCCC2=C1</smiles>

4

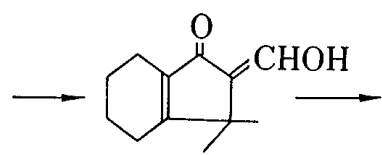

5<smiles>CC(C)(C)c1cnoc2cc3c(c1-2)CCCC3</smiles>

6<smiles>CC1(C)CCCC2=C1C(C)(C)C(C#N)C2=O</smiles>

7

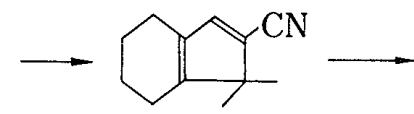

8<smiles>CC(C)(C)C(C=O)=CC1=C2CCCCC2C1</smiles>

9<smiles>CC(C)(C)C(C=CC=O)=CC1=C2CCCCC2=C1</smiles>

11

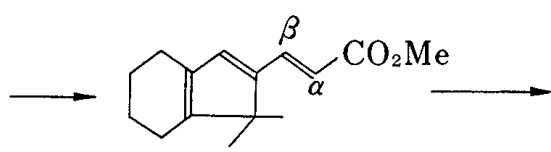

10
3

Chart 1

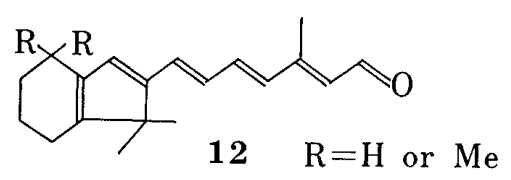

$12 \mathrm{R}=\mathrm{H}$ or $\mathrm{Me}$

trienal $[11, \lambda 363 \mathrm{~nm}, \delta 9.47(\mathrm{~d}, J=8 \mathrm{~Hz}, 1 \mathrm{H}, \mathrm{CHO}), 7.20(\mathrm{~d}, J=16 \mathrm{~Hz}, 1 \mathrm{H}, \beta-\mathrm{H})$, $6.68(\mathrm{~s}, 1 \mathrm{H},=\mathrm{CH}), 6.20(\mathrm{dd}, J=16,8 \mathrm{~Hz}, 1 \mathrm{H}, \alpha-\mathrm{H})]$ in $40 \%$ yield in which the geometry of the $\alpha, \beta$-double bond was preserved. A Wittig reaction between 11 and the triphenylphosphine isopropylidene reagent prepared from isopropyltriphenylphosphonium bromide and $n$-butyl lithium in a pressure bottle under argon, furnished [3, unstable yellow oil, $\mathrm{C}_{17} \mathrm{H}_{24}$, $m / e 228.1897\left(\mathrm{M}^{+}\right), \lambda 347,331,318$ (sh.), $237 \mathrm{~nm}, \delta 6.60$ (dd, $\left.J=16,10 \mathrm{~Hz}, 1 \mathrm{H}, 2^{\prime}-\mathrm{H}\right), 6.22$ $\left(\mathrm{d}, J=16 \mathrm{~Hz}, 1 \mathrm{H}, 1^{\prime}-\mathrm{H}\right), \overline{6.19}(\mathrm{~s}, 1 \mathrm{H}, 3-\mathrm{H}), 5.92\left(\mathrm{~d}, J=10 \mathrm{~Hz}, 3^{\prime}-\mathrm{H}\right), 1.81\left(\mathrm{~s}, 6 \mathrm{H}, 5^{\prime}-\mathrm{H}_{3}\right.$ and $\left.\left.4^{\prime}-\mathrm{CH}_{3}\right), 1.09\left(\mathrm{~s}, 6 \mathrm{H}, 1-\mathrm{gem} \mathrm{CH}_{3}\right)\right]$ in $72 \%$ yield. A Wittig reaction between 9 and dimethylallyltriphenylphosphonium bromide in the presence of $n$-butyl lithium in dry ether produced a mixture $(3: 1)$ of 3 and its cis isomer from which attempts to separate each isomer were unsuccessful. The NMR spectral pattern of 3 in olefinic region was similar to that of 2 . A striking resemblance between the ultraviolet absorption spectrum in EtOH of 3 and that of 2 and a similarity of the visible light absorption spectrum in $74 \% \mathrm{H}_{2} \mathrm{SO}_{4}$ of $\mathbf{3}$ to that of 2 present unambiguous evidence in support of the chromophoric structure of 2 . The present synthesis of 3 which includes a new conjugated system, has resulted in the method for the preparation of 12 which is an interesting compound in the studies of visual pigment analogues. ${ }^{8)}$

8) M. Ito, K. Hirata (née Akutsu), A. Kodama, K. Tsukida, H. Matsumoto, K. Horiuchi and T. Yoshizawa, Chem. Pharm. Bull., 26, 925 (1978); S. Kawamura, T. Yoshizawa, K. Horiuchi, M. Ito, A. Kodama and K. Tsukida, Biochim. Biophys. Acta, 548, 147 (1979); M. Ito, A. Kodama, M. Murata, M. Kobayashi, K. Tsukida, Y. Shichida and T. Yoshizawa, J. Nutr. Sci. Vitaminol., 25, 343 (1979). 
Kobe Women's College of Pharmacy

4-19-1 Motoyamakita-machi,

Higashinada-ku, Kobe 658, Japan

Received October 29, 1979
Masayoshi Ito

Akiko Kodama

KIYOSHI TSUKIDA

\title{
Isolation of Agarofuran-type Sesquiterpenes from Alpinia japonica (Thunb.) Mrg. ${ }^{1)}$
}

\begin{abstract}
A new sesquiterpene, $3 \alpha, 4 \alpha$-oxidoagarofuran (2) was isolated besides 4-hydroxydihydroagarofuran (1), $\alpha$-agarofuran (3) and $\beta$-eudesmol (4) from the rhizomes of Alpinia japonica.

Biogenetically, it is interesting that $\beta$-eudesmol is isolated from same plant together with agarofurans, which possess 10 -epimeric eudesmane carbon skeleton.

Keywords_-Zirgiberaceae; Alpinia japonica (Tнunв.) MrQ.; sesquiterpene; $4 \alpha$ hydroxydihydroagarofuran; $3 \alpha, 4 \alpha$-oxidoagarofuran; $\alpha$-agarofuran; $\beta$-eudesmol; 10 -epieudesmane-type
\end{abstract}

The seeds of Alpinia japonica (Thuns.) Mro. (Zingiberaceae) are used as an aromatic stomachic under the name, “Izu-shukusha" (伊豆縮砂), in Japan.

Several flavonoids (alpinon, izalpinin, kumatakenin and rhamnocitrin) and monoterpenes (camphor and cineole) have been isolated from the seeds by Kimura and co-workers. ${ }^{2)}$ They have also reported the presence of sesquiterpene alcohols in the essential oil of the seeds, but little has been known about their structures. ${ }^{2 d)}$

In this paper, we wish to report the isolation and characterization of four sesquiterpenes including a new compound from the rhizomes of this plant.

The fresh rhizomes were extracted with methanol, and the aqueous methanolic extracts were partitioned with petroleum ether. The petroleum ether soluble fraction was repeatedly separated and purified by silica gel and silver nitrate impregnated silica gel chromatography to give four compounds $(1-4)$.

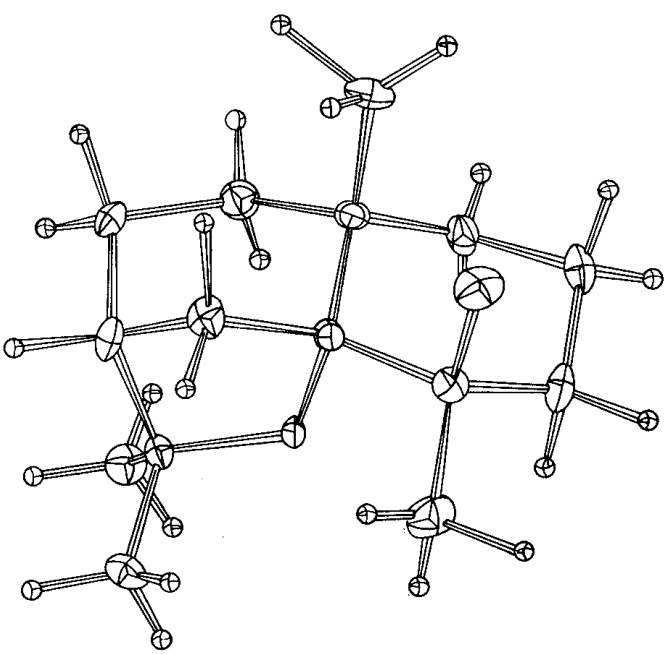

Fig. 1. Perspective View of the Molecular Structure of Compound 1

Compound (1), $\mathrm{C}_{15} \mathrm{H}_{26} \mathrm{O}_{2}$, colorless needles, $\mathrm{mp} 128.5-129.5^{\circ}$, showed a strong hydroxyl absorption band at $3430 \mathrm{~cm}^{-1}$ in the IR spectrum. The ${ }^{1} \mathrm{H}-\mathrm{NMR}$ spectrum $\left(\mathrm{CDCl}_{3}\right)$ revealed. four tertiary methyl signals $(\delta 1.17,1.21,1.27,1.36)$, and the ${ }^{13} \mathrm{C}-\mathrm{NMR}$ spectrum $\left(\mathrm{CDCl}_{3}\right)$ indicated the presence of ether linkage $[\delta 82.1(\mathrm{~s}), 87.8(\mathrm{~s})]$. Taking account of its molecular formula, we assumed from above facts that compound (1) might be $4 \alpha$-hydroxydihydroagaro-

1) Studies on Zingiberaceous Plants. Part $\mathrm{I}$.

2) a) Y. Kimura and M. Hoshi, Yakugaku Zasshi, 57, 147 (1937); b) Y. Kimura and M. Hoshi, ibid., 55, 1101 (1935); c) Y. Kimura, M. Takido and S. Takahashi, ibid., 87, 1132 (1967); d) Y. Kimura and M. Hoshi, ibid., 53, 794 (1933). 